Disclosure of Interests: Stanley B. Cohen Consultant of: AbbVie, Amgen, Boehringer Ingelheim, Gilead, Pfizer, Roche, and Sandoz, Grant/research support from: AbbVie, Amgen, Boehringer Ingelheim, Gilead, Pfizer, Roche, and Sandoz, Ronald van Vollenhoven Consultant of: AbbVie, AstraZeneca, Biotest, Bristol-Myers Squibb, Celgene, Eli Lilly, GSK, Janssen, Medac, MSD, Novartis, Pfizer, Roche, and UCB, Grant/research support from: AbbVie, Arthrogen, Bristol-Myers Squibb, Eli Lilly, GSK, Pfizer, and UCB, Jeffrey R. Curtis Consultant of: AbbVie, Amgen, Bristol-Myers Squibb, Corrona, Crescendo, Janssen, Pfizer, Sanofi/Regeneron, and UCB, Grant/research support from: AbbVie, Amgen, Bristol-Myers Squibb, Corrona, Crescendo, Janssen, Pfizer, Sanofi/Regeneron, and UCB, Leonard Calabrese Speakers bureau: AbbVie, Crescendo, Genentech, Horizon, Janssen, Novartis, and Sanofi, Consultant of: AbbVie, Bristol-Myers Squibb, Crescendo, Genentech, Gilead, GSK, Horizon, Janssen, Novartis, and Sanofi, Cristiano Zerbini Speakers bureau: MSD, Pfizer, and Sanofi, Consultant of: MSD, Pfizer, and Sanofi, Grant/research support from: Amgen, Eli Lilly, GSK, MSD, Novartis, Pfizer, Roche, Sanofi, and Servier, Yoshiya Tanaka Speakers bureau: AbbVie, Asahi Kasei, Astellas, Bristol-Myers Squibb, Chugai, Daiichi Sankyo, Eisai, Eli Lilly, Gilead, GSK, Janssen, Mitsubishi Tanabe, Novartis, Pfizer, Sanofi, and YL Biologics, Grant/research support from: Asahi Kasei, Chugai, Daiichi Sankyo, Eisai, Mitsubishi Tanabe, Takeda, and UCB, Louis Bessette Speakers bureau: AbbVie, Amgen, Bristol-Myers Squibb, Celgene, Eli Lilly, Gilead, Janssen, MSD, Novartis, Pfizer, Roche, Sanofi, and UCB, Consultant of: AbbVie, Amgen, Bristol-Myers Squibb, Celgene, Eli Lilly, Gilead, Janssen, MSD, Novartis, Pfizer, Roche, Sanofi, and UCB, Grant/research support from: AbbVie, Amgen, Bristol-Myers Squibb, Celgene, Eli Lilly, Gilead, Janssen, MSD, Novartis, Pfizer, Roche, Sanofi, and UCB, Christophe Richez Speakers bureau: AbbVie, Amgen, AstraZeneca, Biogen, Bristol-Myers Squibb, Eli Lilly, GSK, MSD, and Pfizer, Consultant of: AbbVie, Amgen, AstraZeneca, Biogen, Bristol-Myers Squibb, Eli Lilly, GSK, MSD, and Pfizer, Ivan Lagunes-Galindo Shareholder of: May own stock or options in AbbVie, Employee of: AbbVie, Jianzhong Liu Shareholder of: May own stock or options in AbbVie, Employee of: AbbVie, Heidi Camp Shareholder of: May own stock or options in AbbVie, Employee of: AbbVie, Yanna Song Shareholder of: May own stock or options in AbbVie, Employee of: AbbVie, Samuel Anyanwu Shareholder of: May own stock or options in AbbVie, Employee of: AbbVie, Gerd Rüdiger Burmester Speakers bureau: AbbVie, Eli Lilly, Gilead, Janssen, MSD, Pfizer, Roche, and UCB, Consultant of: AbbVie, Eli Lilly, Gilead, Janssen, MSD, Pfizer, Roche, and UCB

DOI: 10.1136/annrheumdis-2021-eular.1856

\section{POS0221 COMPARISON OF TOFACITINIB AND BARICITINIB BY INVERSE PROBABILITY OF TREATMENT WEIGHTING ANALYSES BASED ON PROPENSITY SCORE IN PATIENTS WITH RHEUMATOID ARTHRITIS IN REAL CLINICAL PRACTICE}

Y. Miyazaki ${ }^{1}$, S. Nakayamada ${ }^{1}$, K. Nakano ${ }^{1}$, S. Kubo ${ }^{1}$, Y. Inoue ${ }^{1}$, Y. Fujino ${ }^{2}$, Y. Tanaka ${ }^{1}{ }^{1}$ Hospital of University of Occupational and Environmental Health, The First Department of Internal Medicine, Kitakyushu, Japan; ${ }^{2} \mathrm{Hospital}$ of University of Occupational and Environmental Health, Department of Environmental Epidemiology, Institute of Industrial Ecological Sciences, Kitakyushu, Japan

Background: Tofacitinib (TOFA) and baricitinib (BARI) have been widely used in many regions for treatment of rheumatoid arthritis (RA). The selection of JAK inhibitor for RA treatment based on patient type remains a major concern.

Objectives: The differences of efficacy between each Janus kinase (JAK) inhibitors have not been clarified in the patients with RA in clinical practice. Here, we compared the efficacy between TOFA and BARI in clinical practice.

Methods: A retrospective observational study. The efficacy of TOFA $(n=156)$ in patients with RA was compared with BARI $(n=138)$. Selection bias was reduced to a minimum using propensity score-based inverse probability of treatment weighting (IPTW). We analyzed the trajectories of changes in disease activity in patients receiving TOFA or BARI using growth mixture modeling (GMM). Multivariable logistic regression analysis was performed to identify factors contributing to belonging to treatment-resistance group defined by GMM. The observation period of the study was 24 weeks.

Results: No significant difference was observed in patient characteristics between the TOFA and BARI groups in after adjustment by propensity scorebased IPTW. The retention rates over 24 weeks did not differ between the TOFA and BARI groups. No difference was observed in the incidence of adverse events in the TOFA and BARI groups. Clinical disease activity index (CDAI) at week 24 after the introduction of JAK inhibitors was $8.0 \pm 8.9$ and $6.2 \pm 7.2$ in the TOFA and BARI group, respectively. The rates of CDAl-remission at week 24 in the TOFA and BARI groups were $43 / 153(28.3 \%)$ and $57 / 141$ (40.4\%), respectively. Compared to the TOFA group, the BARI group showed a significantly lower CDAI ( $\triangle \mathrm{CDAl}=-1.9,95 \%$ confidence interval: -3.7 to $-0.3, \mathrm{p}=0.02$ ) and a significantly higher rate of CDAl-remission (odds ratio: $1.7,95 \% \mathrm{Cl}: 1.1-2.7, \mathrm{p}=0.04$ ) at week 24. Similarly, at week 24 , SDAI was significantly lower in the BARI group (TOFA vs. $\mathrm{BARI}=10.1 \pm 9.9$ vs. $7.3 \pm 7.5, \Delta \mathrm{SDAl}=-2.2,95 \% \mathrm{Cl}:-4.2$ to $-0.2, \mathrm{p}=0.04)$, and the rates of SDAI-remission (OR: $1.6,95 \% \mathrm{Cl}: 1.0-2.6, \mathrm{p}=0.04$ ).

The patients were divided into two groups: patients with MDA to HDA at baseline (Group 1) and patients with HDA at baseline than Group 1 (Groups 2 and 3) based on the analysis of the trajectories of CDAl using GMM, In Groups 1 and 2 disease activity was improved immediately after the introduction of JAK inhibitors. In Group 3, disease activity was partially improved, and LDA was not achieved at week 24 after the introduction of JAK inhibitors. The patients in Group 3 were resistant to treatment (Group 3: treatment-resistance group).

When multivariable logistic regression analysis was performed for all patients receiving JAK inhibitors, the factors contributing to belonging to treatment-resistance group were: high baseline HAQ-DI score (OR: 1.76, 95\% Cl: 1.09-2.84, $\mathrm{p}=0.02$ ) and high number of biological disease-modifying anti-rheumatic drugs (bDMARDs) used before JAK inhibitors (OR: 1.51, 95\% Cl: 1.16-1.95, p=0.002) and TOFA use (OR: $2.13,95 \% \mathrm{Cl}: 1.05-4.30, \mathrm{p}=0.03$ )

Next, multivariable logistic regression analysis was separately performed for each treatment group. The patients receiving more bDMARDs before the JAK inhibitor were more likely to belong to treatment-resistance group in the TOFA group (OR: 1.76, 95\% Cl: 1.24-4.06). Among patients with RA who received TOFA, those who had received $\geq 4$ bDMARDs before the introduction of TOFA were more likely to be classified into the treatment-resistant group.

In the BARI group, multivariable logistic regression analysis did not identify any factors associated with belonging to treatment-resistance group.

Conclusion: TOFA may be partially effective in patients resistant to many bDMARDs. Consequently, efficacy may differ between TOFA and BARI. Because TOFA was less effective in RA patients resistant to $\geq 4$ bDMARDs, the present study suggests that BARI may be more appropriate for RA patients resistant to many bDMARDs.

Disclosure of Interests: Yusuke Miyazaki Speakers bureau: Eli Lilly, Shingo Nakayamada Speakers bureau: Bristol-Myers, UCB, Astellas, Abbvie, Eisai, Pfizer, Takeda, Kazuhisa Nakano Speakers bureau: Bristol-Myers, Sanofi, AbbVie, Eisai, Eli Lilly, Chugai, Pfizer, Takeda, and Mitsubishi-Tanabe, Satosh Kubo Speakers bureau: Bristol-Myers, Yoshino Inoue: None declared, Yoshihisa Fujino: None declared, Yoshiya Tanaka Speakers bureau: Abbvie, Daiichi-Sankyo, Chugai, Takeda, Mitsubishi-Tanabe, Bristol-Myers, Astellas, Eisai, Janssen, Pfizer, Asahi-kasei, Eli Lilly, GlaxoSmithKline, UCB, Teijin, MSD, and Santen DOI: 10.1136/annrheumdis-2021-eular.2012

\begin{tabular}{|l|l}
\hline POS0222 & PREDICTORS OF RESPONSE: BASELINE \\
CHARACTERISTICS AND EARLY TREATMENT \\
RESPONSES ASSOCIATED WITH ACHIEVEMENT \\
OF REMISSION AND LOW DISEASE ACTIVITY \\
AMONG UPADACITINIB-TREATED PATIENTS WITH \\
RHEUMATOID ARTHRITIS
\end{tabular}

A. Kavanaugh ${ }^{1}$, Z. Szekanecz ${ }^{2}$, E. C. Keystone ${ }^{3}$, A. Rubbert-Roth ${ }^{4}$, S. Hall ${ }^{5}$, R. Xavier ${ }^{6}$, J. Polido-Pereira ${ }^{7}$, I. H. Song ${ }^{8}$, N. Martin ${ }^{9}$, Y. Song ${ }^{8}$, S. Anyanwu ${ }^{8}$, P. Nash ${ }^{10}$. ${ }^{1}$ University of California San Diego, Division of Rheumatology, Allergy and Immunology, Department of Medicine, San Diego, California, United States of America; ${ }^{2}$ University of Debrecen, Division of Rheumatology, Faculty of Medicine, Debrecen, Hungary; ${ }^{3}$ MaRS Center, Rheumatology, Toronto, Ontario, Canada; ${ }^{4}$ Kantonsspital St. Gallen, Rheumatology, St. Gallen, Switzerland; ${ }^{5}$ Emeritus Research and Monash University, Rheumatology, Melbourne, Victoria, Australia; ${ }^{6}$ Hospital de Clínicas de Porto Alegre, Serviço de Reumatologia, Porto Alegre, Brazil; ${ }^{7}$ Hospital de Santa Maria, Centro Hospitalar Universitário Lisboa Norte and Instituto de Medicina Molecular, Faculdade de Medicina, Universidade de Lisboa, Lisbon Academic Medical Centre, Lisbon, Portugal; ${ }^{8}$ AbbVie Inc., Immunology, North Chicago, Illinois, United States of America; ${ }^{9}$ AbbVie Inc., Immunology, Saint Laurent, Quebec, Canada; ${ }^{10}$ University of Queensland, Rheumatology, Brisbane, Queensland, Australia

Background: Upadacitinib (UPA) $15 \mathrm{mg}$ once daily (QD) has demonstrated efficacy in phase 3 studies of patients with rheumatoid arthritis (RA).1-4 Early prediction of response to treatment with UPA could help to optimize therapy. Objectives: To identify baseline (BL) characteristics or Week (Wk) 12 disease activity measures that may predict the achievement of remission (REM) or low disease activity (LDA) at 6 months in patients with RA receiving UPA $15 \mathrm{mg}$. Methods: This ad hoc analysis included patients who were randomized to UPA $15 \mathrm{mg}$ QD, as monotherapy in methotrexate (MTX)-naïve patients (SELECTEARLY) or in combination with conventional synthetic disease-modifying antirheumatic drugs (csDMARDs), in patients with an inadequate response (IR) to MTX (SELECT-COMPARE) or $\geq 1$ tumor necrosis factor inhibitors (TNFis) (SELECT-BEYOND and SELECT-CHOICE). The association of BL characteristics (including age, disease duration, prior/concomitant treatments, C-reac tive protein [CRP], seropositivity, and disease activity) and Wk 12 disease activity parameters with the achievement of Clinical Disease Activity Index (CDAI) REM ( $\leq 2.8)$ or LDA ( $\leq 10)$ at Wk 24 (or Wk 26 in SELECT-COMPARE) was assessed by concordance statistics (C-statistics), or area under the 
receiver operator characteristic curve. C-index values and 95\% confidence intervals were calculated by fitting a univariate logistic regression model for: demographic and BL characteristics, Wk 12 disease activity measures, and change from $\mathrm{BL}$ at $\mathrm{Wk} 12$ in disease activity measures. A multivariate logistic regression with stepwise model selection was also performed. The proportion of patients achieving Wk 24/26 CDAI REM/LDA was stratified by $\geq 50 \%$ improvement from $\mathrm{BL}$ in swollen and/or tender joint count in 66/68 joints (SJC66/TJC68).

Results: A total of 1377 patients were included in the analysis. Across the 4 studies, CDAI REM and LDA were achieved in $11.0-28.4 \%$ and $50.0-58.6 \%$ of patients, respectively (Table 1). BL demographics and disease characteristics were weakly predictive $(C$-index $<0.70)$ of Wk 24/26 CDAI REM (C-index 0.490.69) or LDA (C-index 0.47-0.65), with the exception of BL Health Assessment Questionnaire-Disability Index in SELECT-BEYOND, which was moderately predictive of CDAI REM (C-index 0.73). Changes from $\mathrm{BL}$ in disease activity measures at Wk 12 were weakly or moderately predictive of Wk 24/26 CDAl REM (Figure 1) or LDA. CDAl value at Wk 12 was strongly predictive (C-index $>0.80$ ) of Wk 24/26 CDAI REM or LDA. Disease Activity Score in 28 joints using CRP and pain at Wk 12 were strongly predictive of Wk 24/26 CDAI REM (except in SELECT-CHOICE). Physician's global assessment at Wk 12 was the only common predictor in the multivariate regression models for CDAI REM/LDA at Wk $24 / 26$ across the 4 studies. A greater proportion of patients achieving $\geq 50 \%$ improvement in SJC66 and TJC68 at Wk 12 achieved CDAI REM (16.5-37.8\% vs $0-9.4 \%)$ or LDA $(66.0-72.8 \%$ vs $20.9-35.7 \%)$ at Wk $24 / 26$ than those who did not.

Conclusion: BL characteristics did not strongly predict response to UPA, but composite disease activity scores at Wk 12 predicted Wk 24/26 REM/LDA with UPA $15 \mathrm{mg}$ QD across MTX-naïve, MTX-IR, and TNFi-IR patients. $\geq 50 \%$ improvement in SJC/TJC at Wk 12 was also associated with Wk 24/26 REM/LDA. REFERENCES:

[1] van Vollenhoven R, et al. Arthritis Rheumatol 2020;72:1607-20; 2. Genovese MC, et al. Lancet 2018;391:2513-24; 3. Fleischmann R, et al. Arthritis Rheumatol 2019;71:1788-800; 4. Rubbert-Roth A, et al. N Engl J Med 2020;383:1511-21

Table 1. Achievement of CDAI LDA and REM at Wk $24 / 26^{a}$

\begin{tabular}{|c|c|c|c|c|}
\hline \multirow{3}{*}{$\begin{array}{l}\text { Patient population } \\
\text { Treatment }\end{array}$} & \multirow{2}{*}{$\begin{array}{l}\text { SELECT-EARLY } \\
\text { n MTX-naïve }\end{array}$} & \multirow{2}{*}{$\begin{array}{r}\begin{array}{l}\text { SELECT- } \\
\text { COMPARE }\end{array} \\
\text { MTX-IR }\end{array}$} & \multicolumn{2}{|c|}{ SELECT-BEYONDSELECT-CHOICE } \\
\hline & & & TNFi-IR & TNFi-IR \\
\hline & $\begin{array}{l}\text { UPA } 15 \mathrm{mg} \text { mono- } \\
\text { therapy }(\mathrm{n}=317)\end{array}$ & $\begin{array}{c}\text { UPA } 15 \mathrm{mg}+\text { MTX } \\
(\mathrm{n}=651)\end{array}$ & $\begin{array}{c}\text { UPA } 15 \mathrm{mg}+ \\
\text { csDMARD } \\
(\mathrm{n}=146)\end{array}$ & $\begin{array}{l}\text { UPA } 15 \mathrm{mg}+ \\
\text { csDMARD } \\
(\mathrm{n}=263)\end{array}$ \\
\hline \multicolumn{5}{|c|}{ Efficacy at Wk $24 / 26^{a}, n(\%)$} \\
\hline CDAI REM ( $\leq 2.8)$ & $90(28.4)$ & $150(23.0)$ & $16(11.0)$ & $60(22.8)$ \\
\hline CDAI LDA $(\leq 10)$ & $178(56.2)$ & $343(52.7)$ & $73(50.0)$ & $154(58.6)$ \\
\hline
\end{tabular}

${ }^{\mathrm{a}}$ Wk 26 for SELECT-COMPARE only

Acknowledgements: AbbVie funded this study; contributed to its design; participated in data collection, analysis, and interpretation of the data; and participated in the writing, review, and approval of the abstract. No honoraria or payments were made for authorship. Medical writing support was provided by Laura Chalmers, $\mathrm{PhD}$, of 2 the Nth (Cheshire, UK), and was funded by AbbVie.

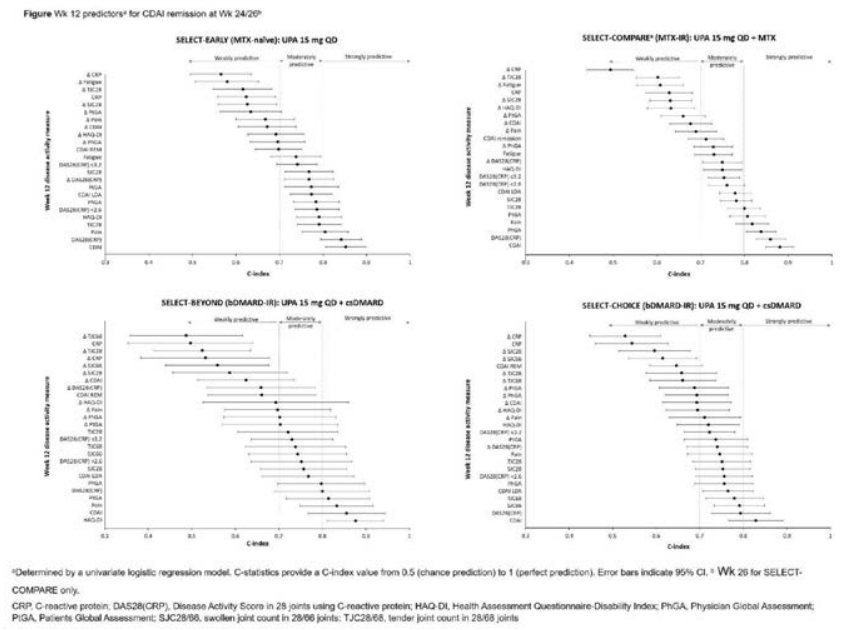

Disclosure of Interests: Arthur Kavanaugh Consultant of: Janssen, Grant/ research support from: Janssen, Zoltán Szekanecz: None declared, Edward C.
Keystone Speakers bureau: Abbott, Amgen, AstraZeneca, Biotest, Bristol-Myers Squibb, Eli Lilly, Genentech, Janssen, MSD, Novartis, Pfizer, Roche, Sanofi, and UCB, Consultant of: Abbott, Amgen, AstraZeneca, Biotest, Bristol-Myers Squibb, Eli Lilly, Genentech, Janssen, MSD, Novartis, Pfizer, Roche, Sanofi, and UCB, Grant/research support from: Abbott, Amgen, AstraZeneca, Biotest Bristol-Myers Squibb, Eli Lilly, Genentech, Janssen, MSD, Novartis, Pfizer, Roche, Sanofi, and UCB, Andrea Rubbert-Roth Consultant of: AbbVie, Amgen Bristol-Myers Squibb, Chugai, Eli Lilly, Janssen, Novartis, Pfizer, Roche, and Sanofi, Stephen Hall Grant/research support from: Pfizer, Ricardo Xavier: None declared, Joaquim Polido-Pereira: None declared, In-Ho Song Shareholder of: May own stock or options in AbbVie, Employee of: AbbVie, Naomi Martin Shareholder of: May own stock or options in AbbVie, Employee of: AbbVie, Yanna Song Shareholder of: May own stock or options in AbbVie, Employee of: AbbVie, Samuel Anyanwu Shareholder of: May own stock or options in AbbVie, Employee of: AbbVie, Peter Nash Grant/research support from: AbbVie Bristol-Myers Squibb, Celgene, Eli Lilly, Gilead, Janssen, MSD, Novartis, Pfizer Roche, Sanofi, and UCB.

DOI: 10.1136/annrheumdis-2021-eular.2137

\section{\begin{tabular}{|l|l}
\hline POS0223 PATTERNS OF JANUS KINASE INHIBITOR CYCLING \\
\hline
\end{tabular} FOR THE MANAGEMENT OF RHEUMATOID ARTHRITIS IN REAL-WORLD CLINICAL PRACTICE: AN ANALYSIS OF THE OPAL DATASET}

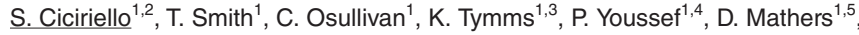
C. Deakin ${ }^{1}$, H. Griffiths ${ }^{1,6}$, G. Littlejohn ${ }^{1,7}$. ${ }^{1}$ OPAL Rheumatology, Ltd., Sydney, Australia; ${ }^{2}$ Dept. Rheumatology, Royal Melbourne Hospital, Melbourne, Australia; ${ }^{3}$ Canberra Rheumatology, Canberra, Australia; ${ }^{4}$ Dept. Rheumatology, Royal Prince Alfred Hospital, Camperdown, Australia; ${ }^{5}$ Georgetown Arthritis, Georgetown, Australia; ${ }^{6}$ Barwon Rheumatology, Services, Geelong, Australia; ${ }^{7}$ Dept. of Medicine, Monash University, Clayton, Australia

Background: There are currently eleven biologic and targeted synthetic (b/ts) DMARDs acting via five different modes of action available for the treatment of RA in Australia. The cost of b/tsDMARDs is subsidized by government for patients that have active RA despite six months of combination csDMARD therapy. Once a patient is eligible, the clinician can prescribe the b/tsDMARD they deem to be the most clinically appropriate for the patient. In Oct 2015 the firs JAK inhibitor (JAKi) became available in Australia (tofacitinib, TOF), baricitinib (BARI) became available in Sept 2018, and upadacitinib (UPA) in May 2020 Each of these oral tsDMARDs possess different selectivity profiles towards different members of the JAK family (JAK1-3 and Tyk2).

Objectives: The aim of this analysis was to determine the patterns of JAKi cycling in real-world practice in Australia.

Methods: Deidentified clinical data were sourced from the OPAL dataset, which is collected in a custom-built electronic medical record during the routine consultation ${ }^{1}$. Data from patients $>18$ years with RA who commenced a b/tsDMARD between Jan-2007 and Dec-2020 were included in the analysis. A visual analytics software program was used to display data on medication initiation and cessation dates, and reasons for stopping tsDMARDs, which is recorded in the medical record at the time of the decision.

Results: At Dec 2020, 28\% of the 52,190 patients with RA in the OPAL datase were prescribed b/tsDMARDs. Of these patients, 3,850 (26.3\%) were currently prescribed a JAKi with $51.4 \%$ receiving TOF, 29.2\% BARI and $19.4 \%$ UPA. In 2020, JAKi initiations accounted for $48.8 \%$ of all initiations and $30.7 \%$ of $1^{\text {st }}$ line initiations; an increase of $6.1 \%$ and $3.5 \%$ from 2019 , respectively. The percentage of patients switching from a first line JAKi to a second line JAKi rather than an agent with another mode of action increased from $33.1 \%$ in 2019 to $42.6 \%$ in 2020. This is despite $26.2 \%$ in 2019 and $45.8 \%$ in 2020 of the patients switching to another JAKi citing lack of efficacy as the reason for JAKi discontinuation. In the period between May 2020, when a third JAKi (UPA) become available, and Dec 2020, the majority of patients switching from first line TOF or BARI to another JAKI switched to UPA $(69.4 \%$ and $83.9 \%$, respectively) whilst $30.6 \%$ of first line TOF patients switched to BARI $(30.6 \%)$, and $16.1 \%$ of first line BARI patients switched to TOF in second line. The majority of patients switching from second line TOF or BARI to a third line JAKi switched to UPA ( $73 \%$ and $96 \%$, respectively), with $27 \%$ of second line TOF patients switching to BARI and a very low number moving from second line BARI to TOF (4\%). JAKi choice after a third line TOF or BARI was almost exclusively UPA $(86.2 \%$ and $95.5 \%$, respectively).

Conclusion: There has been significant and sustained uptake of JAKi for the management of RA in Australia and JAKi cycling is increasingly common in routine clinical care. Clinical outcomes and persistence following JAKi cycling requires further investigation.

\section{REFERENCES:}

[1] Littlejohn GO, Tymms KE, Smith T, Griffiths HT. Using big data from realworld Australian rheumatology encounters to enhance clinical care and research. Clin Exp Rheumatol. Sep-Oct 2020;38(5):874-880. 